\title{
A METHOD FOR ENERGY CONSUMPTION ASSESSMENT BY OPERATION OF BEV'S IN DIFFERENT ROAD CONDITIONS
}

\author{
Lech J. Sitnik \\ Wroclaw University of Science and Technology \\ Mechanical Faculty, Vehicle Engineering Division \\ Wybrzeże Stanisława Wyspiańskiego Street 27, 50-370 Wroclaw, Poland \\ tel.: +48713477918, fax: +48713477918 \\ e-mail: lech.sitnik@pwr.edu.pl
}

\begin{abstract}
For the third time in the history of humankind, it is trying to implement e-mobility. There is a reasonable hope that this attempt will succeed this time. E-mobility is generally regarded as a zero emission. This sentence can only be true in a very small scope, as only in relation to selected parameters and in a very limited its dimension. The situation can change radically. If it will be take into account, the emissions in the production of electricity is necessary for the movement of this type of vehicles Second problem is the energy use amount. We know today that the energy consumption of electric cars, especially in long-term operation is too big. This general knowledge is not confirmed by research results. Both relevant databases and methods of their analysis are missing. This is an unfavourable situation because it is not possible to verify the effects of various changes introduced e.g. in the construction or technology of cars. This publication can be included in those in which it is shown how to change this situation.

The analysis of the results of long-term car use can be used as a verification of various development works, especially in e-mobility, which is only just starting. In the future, it will be need to create the appropriate "big data" databases and a number of tools to analyse the data collected there.
\end{abstract}

Keywords: transport, road transport, battery energy vehicles, energy consumption

\section{Introduction}

For the third time in the history of humankind, it is trying to implement e-mobility. There is a reasonable hope that this attempt will succeed this time. Such premises are quite important. On the one hand, modern electric cars (BEV) are based on outdated technical and technological solutions, which results in:

- excessive energy demand for vehicle operation (their weight is much higher than it should mainly due to the excessive weight of batteries - on average 10 times greater than the weight of tanks of cars with engines fuelled with liquid fuels for a comparable range) $[1,6,7,8,9]$,

- too long charging time (several dozen times more than refuelling vehicles),

- strong dependence the range on the temperature.

On the other hand:

- reduction of greenhouse gas emissions (and a number of other components, including toxic ones),

- independence from sources of fuel,

- energy security (with a dispersed energy system),

- new and stable jobs in the creation and operation of energy infrastructure.

The above-mentioned positive features of e-mobility outweigh the negatives of its introduction, regardless of the outdated depends construction and technology of the vehicles themselves.

All this is true but with one premise, namely that electricity for e-mobility comes entirely from renewable resources.

The implementation of e-mobility requires, among other things, knowledge of the electricity demand necessary for the operation of vehicles. Important is the knowledge of the assessment of 
the impact of implementing e-mobility on a number of phenomena what requires knowledge of life cycle assessment (LCA) of vehicles and systems.

In both cases, it is necessary to know the need for electricity for the long-term operation of vehicles.

In addition, this - the assessment of the demand for electricity for long-term use of vehicles is the subject of this publication.

\section{Energy economy (EE)}

Traditionally, one of the indicators used to assess the energy demand of vehicle traffic is fuel economy, most often in litters of fuel consumed per 100 kilometres of mileage.

The variation of this indicator is the reverse indicator given as the number of miles driven on one gallon of fuel.

For the sake of this tradition, an indicator suitable for battery electric cars (BEV's) can be provided, in form the demand for electricity necessary to travel a hundred kilometres, expressed in $\mathrm{kWh} / 100 \mathrm{~km}$.

This indicator can be determined in various test conditions, e.g. according to the WLTP test (Worldwide Harmonized Light Vehicles Test Procedure) or in various road tests, e.g. under the conditions of the RDE (Real Driving Emissions) test. Fig. 1 gives an example of the EE results of testing several BEV's of various types, obtained under RDE test conditions.

The figure also shows the range of individual vehicles as RANGE (operation) designated under the RDE conditions and for comparison the coverage of the same type of vehicles but calculated from energy demand data determined in the WLTP.

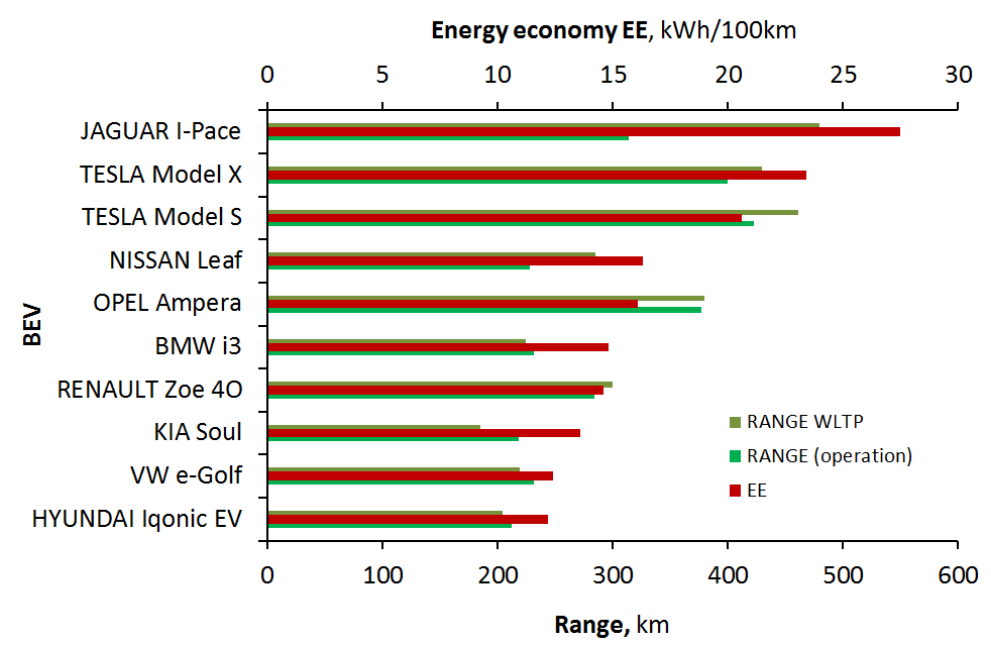

Fig. 1. Energy economy and range of different BEV's (on basis of [2])

It is interesting that cars with low energy demand are also characterized by a small range. This is obvious if it were considered the relatively low capacity of his batteries.

It is also interesting that in the case of higher energy demand, the results obtained in the WLTP test are better than in the operating conditions according to the RDE test. However, with less energy demand, the opposite is true.

This kind of curiosities is more. Fig. 2 presents the results of tests according to the RDE test but obtained in various driving conditions and on different road sections.

It can be see that the differences in energy economy (EED) can reach up to $100 \%$.

This situation raises questions not so much about the sense of conducting research according to WLTP or RDE procedures, but about whether there is an unambiguous method of verifying these results. 


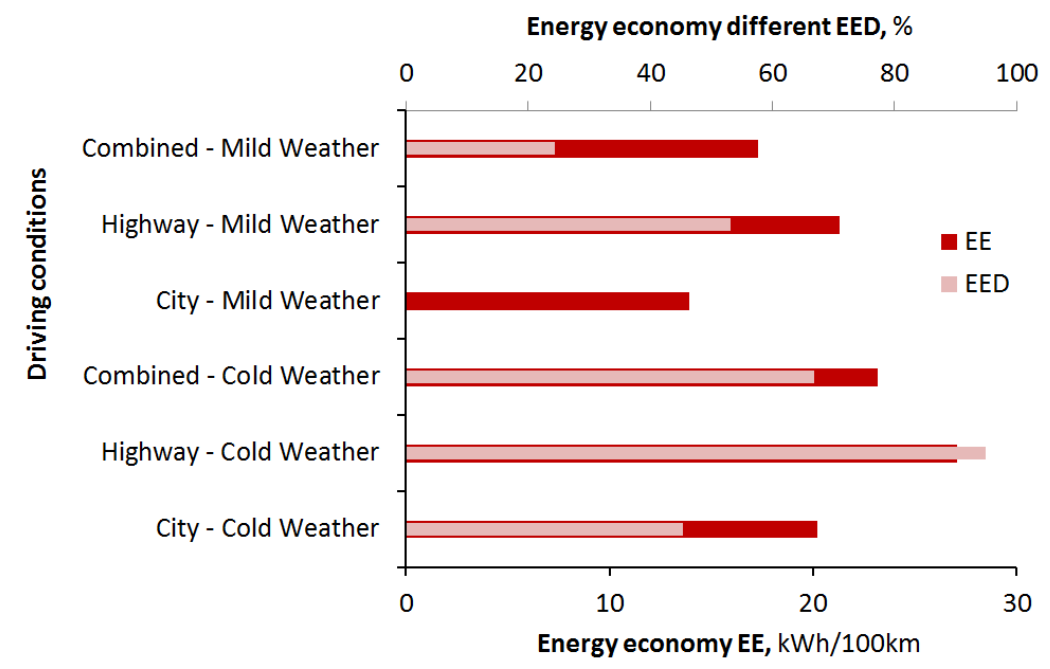

Fig. 2. Energy economy of TESLA Model-S-P100D car (BEV) by different driving conditions [3]

It seems that the answer to this question is yes, but provided that BEV's energy needs are verified using the authors method of determining the cumulative energy demand in long-term operation.

This method is presented in the next chapter of this work.

\section{Example of using of long term BEV's operation data}

It is known that all development works, for example on electric cars, are verified in their longterm operation. Naturally, this also applies to the basic problem such as energy demand for vehicle operation. Everyone knows that. The problem is obtaining reliable data from independent sources.

The development of the data acquisition motivation, however, allows us to hope that such data becomes more and more available. An example of this is the web site spritmonitor.de [4] where particularly useful data are collected.

The commonly available data from this website (spritmonitor.de) regarding LEAF cars are further used. An example of available data is presented in Fig. 3 as the print screen of the page.

The data collected on the website can be used for many different analyses. In addition to the basic data for the car, data on fuel consumption (energy) are aggregated.

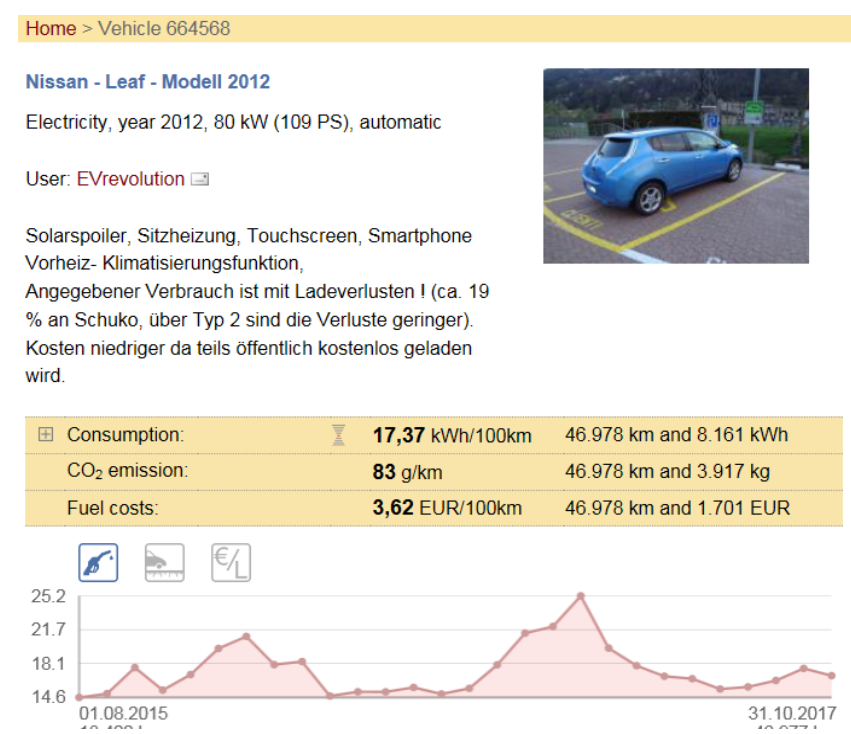

Fig. 3. Print screen of web site spritmonitore.de with main data for vehicle 664568 
Figure 4 shows an example of the data collected on the page.
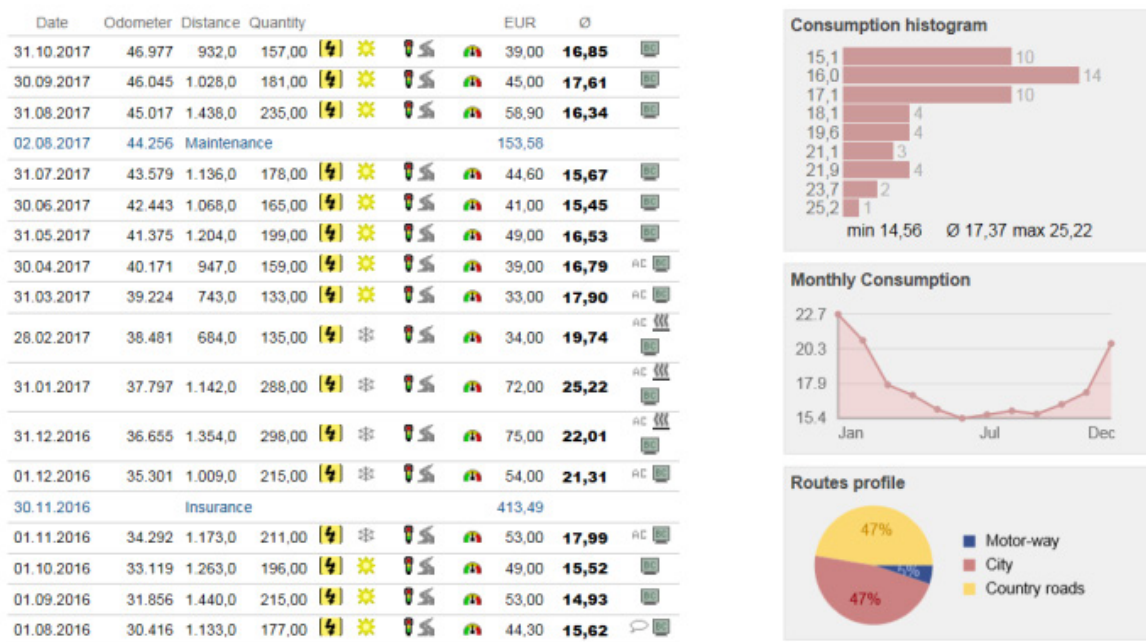

Fig. 4. Data example for vehicle 664568

With the data collected by users (among other things) of LEAF cars (type as in Fig. 3), the energy consumption of 26 such vehicles was analysed.

Figure 5 gives the mileages of these cars. It follows that in the majority of cases these courses covered tens of thousands of kilometres, and only in a few cases a few thousand. It can therefore be assumed that the long-term operation of vehicles was analysed. Not without significance is also the fact that in most cases, not from start mileages were analysed. The analyses are related to cars with different wear of vehicle components.

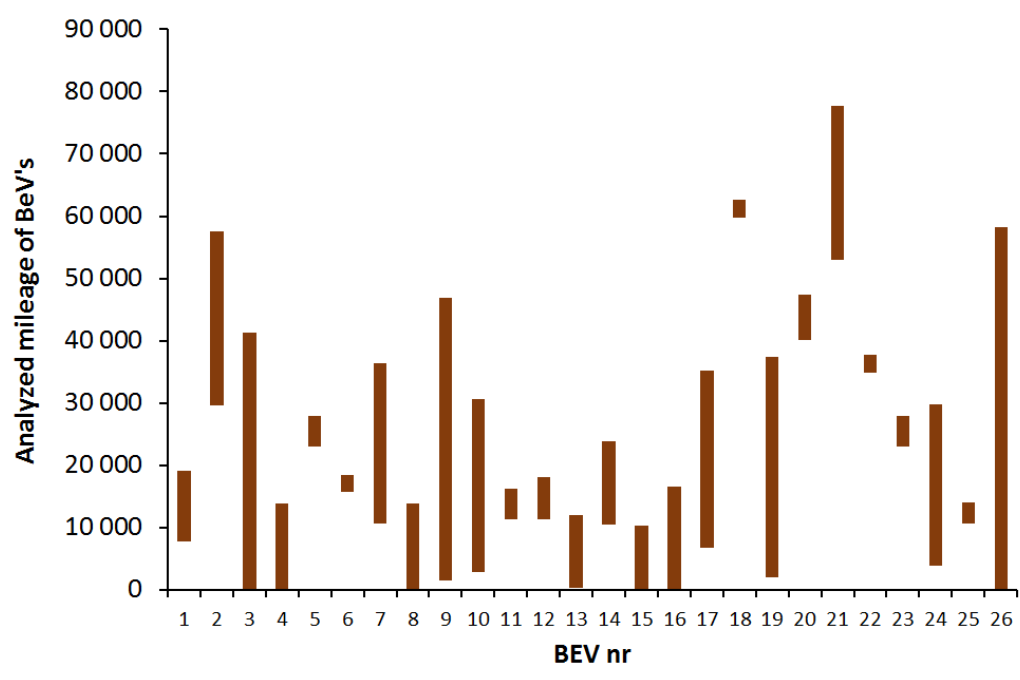

Fig. 5. Mileages of analysed vehicles

Figure 4 shows (in the upper right corner) a histogram of energy economy values after each charging of car batteries. The range, in which the value of this indicator occurs, is also given. The histogram shows quite high variability of this indicator, from 14.56 to $25.22 \mathrm{kWh} / 100 \mathrm{~km}$, with an average value of $17.37 \mathrm{kWh} / 100 \mathrm{~km}$. This average value of the indicator (EE) is also as a "Consumption" in Fig. 3 given. For the analyses presented in this article, the data shown in the lower right corner of Fig. 4, i.e. "Routes profile", are also relevant. These data refer to the share of driving on specific types of roads in the completely analysed car mileage.

Data from the web site can be collected for each of the vehicles that have been replaced there. In the case of 26 LEAF cars analysed, they are presented below in Tab. 1. 
Tab. 1. Operation data for analysed LEAF BEV's

\begin{tabular}{|c|c|c|c|c|c|c|c|c|}
\hline $\begin{array}{l}\text { BEV } \\
\text { No. }\end{array}$ & Vehicle & $\begin{array}{c}\text { Motorway, } \\
\mathrm{S}_{1}\end{array}$ & $\begin{array}{l}\text { City, } \\
\mathrm{S}_{2}\end{array}$ & $\begin{array}{l}\text { Country } \\
\text { roads, } \mathrm{S}_{3}\end{array}$ & $\begin{array}{c}\begin{array}{c}\text { EE, } \\
\mathrm{kWh}\end{array} \\
100 \mathrm{~km}\end{array}$ & $\begin{array}{c}\begin{array}{c}\mathrm{EEc}, \\
\mathrm{kWh}\end{array} \\
100 \mathrm{~km}\end{array}$ & $\begin{array}{c}(\mathrm{EEc}-\mathrm{EE}), \\
\frac{\mathrm{kWh}}{100 \mathrm{~km}}\end{array}$ & $\begin{array}{c}(\mathrm{EEc}-\mathrm{EE}) \\
\mathrm{EEc} \\
\%\end{array}$ \\
\hline 1 & 788087 & 0.92 & 0.08 & 0.00 & 21.98 & 21.52 & -0.46 & -2.13 \\
\hline 2 & 840819 & 0.50 & 0.50 & 0.00 & 19.50 & 19.87 & 0.37 & 1.84 \\
\hline 3 & 622240 & 0.86 & 0.10 & 0.04 & 20.51 & 21.05 & 0.54 & 2.57 \\
\hline 4 & 599039 & 0.68 & 0.23 & 0.09 & 19.62 & 20.05 & 0.43 & 2.14 \\
\hline 5 & 824731 & 0.19 & 0.79 & 0.02 & 17.58 & 18.53 & 0.95 & 5.11 \\
\hline 6 & 880420 & 0.47 & 0.47 & 0.06 & 19.02 & 19.40 & 0.38 & 1.94 \\
\hline 7 & 638443 & 0.23 & 0.69 & 0.08 & 17.83 & 18.33 & 0.50 & 2.75 \\
\hline 8 & 599039 & 0.30 & 0.65 & 0.05 & 19.62 & 18.79 & -0.83 & -4.44 \\
\hline 9 & 664568 & 0.12 & 0.71 & 0.17 & 17.43 & 17.37 & -0.06 & -0.32 \\
\hline 10 & 774923 & 0.10 & 0.45 & 0.45 & 16.76 & 15.66 & -1.10 & -7.04 \\
\hline 12 & 835074 & 0.06 & 0.45 & 0.48 & 16.40 & 16.62 & 0.22 & 1.35 \\
\hline 13 & 694399 & 0.35 & 0.26 & 0.40 & 15.41 & 15.63 & 0.22 & 1.43 \\
\hline 14 & 797218 & 0.35 & 0.13 & 0.52 & 16.22 & 16.23 & 0.01 & 0.08 \\
\hline 15 & 615868 & 0.48 & 0.02 & 0.50 & 15.51 & 16.86 & 1.35 & 8.02 \\
\hline 16 & 687691 & 0.02 & 0.49 & 0.49 & 15.30 & 15.11 & -0.19 & -1.27 \\
\hline 17 & 741949 & 0.04 & 0.10 & 0.86 & 12.73 & 13.02 & 0.29 & 2.24 \\
\hline 18 & 848140 & 0.01 & 0.03 & 0.96 & 11.81 & 12.32 & 0.51 & 4.13 \\
\hline 19 & 807008 & 0.34 & 0.23 & 0.43 & 15.49 & 16.72 & 1.23 & 7.36 \\
\hline 21 & 820587 & 0.05 & 0.14 & 0.81 & 12.27 & 13.35 & 1.08 & 8.12 \\
\hline 22 & 820410 & 0.00 & 0.20 & 0.80 & 14.11 & 13.22 & -0.89 & -6.77 \\
\hline 23 & 822633 & 0.02 & 0.41 & 0.57 & 15.15 & 14.64 & -0.51 & -3.49 \\
\hline 24 & 750404 & 0.86 & 0.12 & 0.02 & 23.23 & 21.17 & -2.06 & -9.74 \\
\hline 25 & 718478 & 0.03 & 0.24 & 0.73 & 14.63 & 13.74 & -0.89 & -6.45 \\
\hline 26 & 731027 & 0.04 & 0.20 & 0.76 & 14.70 & 13.61 & -1.09 & -8.03 \\
\hline
\end{tabular}

With the data as in Tab. 1, one can attempt to find a relationship between energy economy and which types of roads were driven by the vehicle. Thus, for example, the dependence of the following type should be found

$$
\mathrm{EE}=\mathrm{b}_{0}+\mathrm{b}_{1} \mathrm{~S}_{1}+\mathrm{b}_{2} \mathrm{~S}_{2}+\mathrm{b}_{3} \mathrm{~S}_{3}, \text { where } \mathrm{S}_{1}+\mathrm{S}_{2}+\mathrm{S}_{3}=1,
$$

where:

EE - energy economy,

$\mathrm{b}_{0}, \mathrm{~b}_{1}, \mathrm{~b}_{2}, \mathrm{~b}_{3}$ - coefficients,

$\mathrm{S}_{1}$ - share of the on motorway driving in the mileage,

$\mathrm{S}_{2}$ - share of the on city roads driving in the mileage,

$\mathrm{S}_{3}$ - share of the on country roads driving in the mileage.

If the values from the columns of Tab. 1 containing $S_{1}, S_{2}, S_{3}$ should be treated as a matrix of influence factors and the values from the EE column should be treated as the object's response vector, the values of coefficients $b_{0}, b_{1}, b_{2}, b_{3}$ are obtained using standard regression analysis [5]. In this case (Tab. 2).

The model (1) has therefore a specific form (with EEc as a calculated energy economy)

$$
\mathrm{EEc}=147.94-126.10 \mathrm{~S}_{1}-130.04 \mathrm{~S}_{2}-135.89 \mathrm{~S}_{3} .
$$

In the Tab. 3 are the parameters of model (2) predictions given. 
Tab. 2. Values of $b_{0}, b_{1}, b_{2}, b_{3}$ coefficients

\begin{tabular}{|l|l|}
\hline $\mathrm{b}_{0}=$ & 147.93717 \\
\hline $\mathrm{b}_{1}=$ & -126.1007 \\
\hline $\mathrm{b}_{2}=$ & -130.0413 \\
\hline $\mathrm{b}_{3}=$ & -135.8921 \\
\hline
\end{tabular}

Tab. 3. Parameters of model (2) predictions

\begin{tabular}{|l|r|}
\hline Multiple R & 0.9585889 \\
\hline $\mathrm{R}^{2}$ & 0.9188926 \\
\hline Adjusted $\mathrm{R}^{2}$ & 0.9067265 \\
\hline Standard deviation & 0.9034024 \\
\hline
\end{tabular}

As can be see, the model's match ratios have a relatively high value. Therefore, it can be expect good prediction. A graphic illustration of this match is shown in Fig. 6.

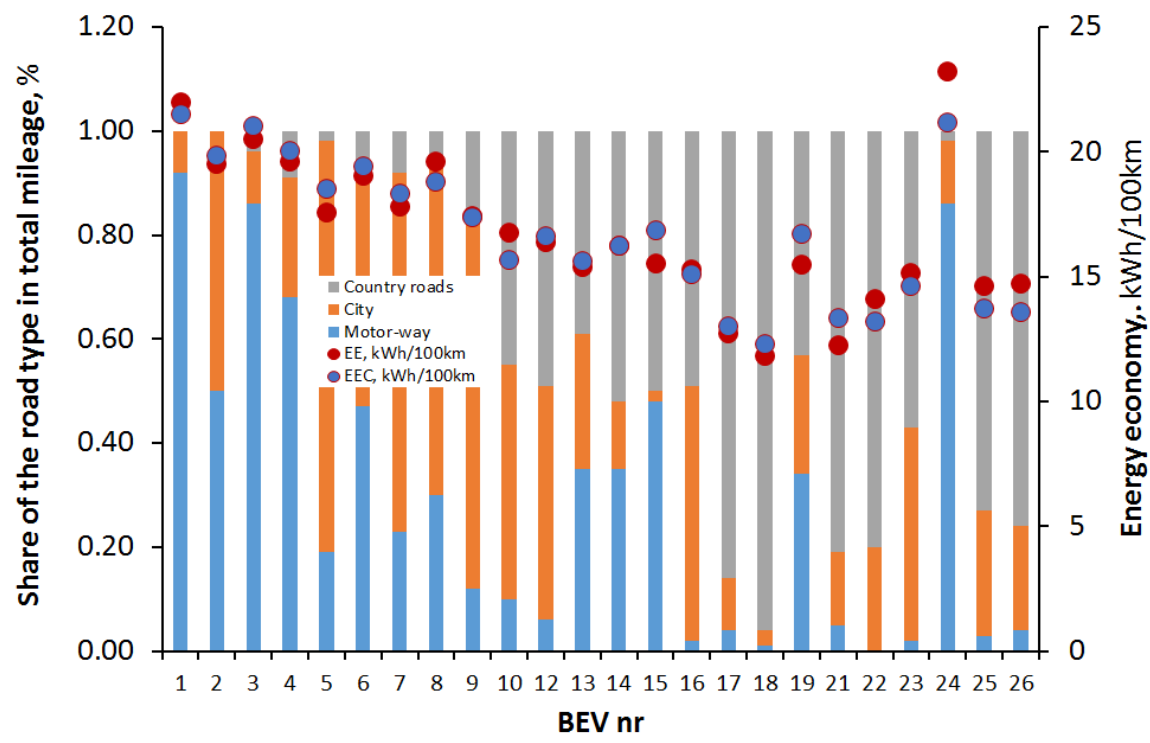

Fig. 6. Share of the driving mileage on different roads and energy economy (EE) and their by model prediction (EEc) of analysed cars

As it can be see, the model describes well the data from the long-term use of vehicles. The deviations of the EE index from its average value in the operation of particular BEV operation result from the fact that the conditions of vehicle operation cover not only the type of roads but, for example, driver's temperament or weather conditions (Fig. 2).

It is interesting that, as it results from the model, the greatest demand for energy occurs in the movement of electric vehicles on the highway, secondly in the city. During the operation of vehicles with combustion engines [10,11], this order is reversed. Driving on country road requires the least energy. If these regularities also apply to other types of cars, then it will be necessary to consider how to interpret the WLTP test message.

\section{Conclusions}

The results obtained seem to be interesting.

It was confirmed that the operational demand for electric energy in the long-term use of electric cars could be very diverse. This is evidenced by the large dispersion of the energy economy indicator (shown here, for example, in Fig. 4). 
However, taking into account their average values, it is possible to create a mathematical model describing, for example, the dependence of the value of the energy economy index as a function of the share of particular operating conditions - here the type of roads on which the cars move.

The use of the model leads to the conclusion that the greatest energy demand occurs when navigating the motorway. This is different from what has so far been found in the operation of cars with internal combustion engines. Up to now, the largest fuel consumption was recorded while driving in the city. If these regularities also apply to other types of cars, then it will be necessary to consider how to interpret the WLTP test message.

In general, it can be said that the analysis of the results of long-term car use can be used as a verification of various development works, especially in e-mobility, which is only just starting. Hence, in the future, it will be need to create the appropriate "big data" databases and a number of tools to analyse the data collected there.

\section{References}

[1] Haller, P., Jankowski, A., Kolanek, C., Walkowiak, W., Potential Non-Toxic Aqueous Emulsion as a Diesel Fuel, Journal of KONES, Vol. 22, Issue 3, DOI: 10.5604/12314005.1165969, pp. 43-48, Warsaw 2015.

[2] http://autobest.org/first-european-independent-ev-real-range-test-press-release/.

[3] https://ev-database.org/car/1075/Tesla-Model-S-P100D.

[4] https://www.excel-easy.com/examples/regression.html.

[5] https://www.google.pl/search? source=hp\&ei=asQTXfzIJe21rgTuvK YBQ\&q=spritmonitor.d e\&oq $=$ spritmonitor.de\&gs_l=psyab.1.0.012j0i3013j0i10i30j0i3014.1861.69589809000.246.1310.14j0j101gwswiz0.0i131.JNQQgFG9FA8.

[6] Jankowski, A., Chosen Problems of Combustion Processes of Advanced Combustion Engine, Journal of KONES, Vol. 20, Issue 3, DOI: 10.5604/12314005.1136852, pp. 203-208, Warsaw 2013.

[7] Kowalski, M., Jankowski, A., Research Performance of Novel Design of Diesel Engine, Journal of KONES, Vol. 24, Issue 4, DOI: 10.5604/01.3001.0010.3157, pp. 99-108, Warsaw 2017.

[8] Kowalski, M., Jankowski, A., Researches of a Combustion Engine Fuelled with a Fuel-Water Microemulsion, Journal of KONES, Vol. 25, Issue 4, DOI: 10.5604/01.3001.0012.4791, pp. 187-196, Warsaw 2018.

[9] Stezycki, P., Kowalski, M., Jankowski, A., Engine Researches on the Influence of the Piston Ring Insert on Temperature Distribution in Piston, Journal of KONES, Vol. 25, Issue 4, DOI: 10.5604/01.3001.0012.7995 pp. 563-570. Warsaw 2018.

[10] Zurek, J., Jankowski, A., Experimental and Numerical Modelling of Combustion Process of Liquid Fuels under Laminar Conditions, Journal of KONES, Vol. 21, Issue 3, pp. 309-316, Warsaw 2014.

[11] Zurek, J., Kowalski, M., Jankowski, A., Modelling of Combustion Process of Liquid Fuels under Turbulent Conditions, Journal of KONES, Vol. 22, Issue 4, DOI: 10.5604/12314005.1168562, pp. 355-364, Warsaw 2015. 